\title{
Genomic characteristics of natural recombinant infectious bronchitis viruses isolated in Korea
}

\author{
Hyun-Woo Moon, Haan Woo Sung, Hyuk Moo Kwon* \\ Laboratory of Veterinary Microbiology, College of Veterinary Medicine and Institute of Veterinary Science, \\ Kangwon National University, Chuncheon 24341, Korea
}

\begin{abstract}
Two infectious bronchitis virus (IBV) K046-12 and K047-12 strains were isolated and the nearly complete genomes of them were sequenced. Sequence comparisons showed that the K046-12 genome was most similar to Korean IBV strains, and the K047-12 genome was most similar to QX-like IBV strains. Phylogenetic analysis showed that nearly all K046-12 and most K046-12 genes were placed in the same cluster as Korean IBV isolates, but the S1 region was placed in the same cluster as Mass-type IBVs. For K047-12, nearly all K047-12 and most K047-12 genes were located in the same cluster as QX-like IBVs, but the M region was located in the same cluster as Korean IBV isolates with K047-12. Recombination analysis confirmed that K046-12 is a recombinant strain with the primary parental sequence derived from Korean IBVs and minor parental sequence derived from Mass-type IBV, and K04712 is a recombinant strain with the major parental sequence derived from QX-IBV and minor parental sequence derived from Korean IBVs. This study showed that new IBV recombinants are constantly generated among various IBVs, including those used for vaccination. Therefore, genetic analysis of new virus isolates should be performed for effective infectious bronchitis control and appropriate vaccine development.
\end{abstract}

Keywords: infectious bronchitis virus; recombinant; sequence; phylogenetic trees

*Corresponding author

Hyuk Moo Kwon

Laboratory of Veterinary Microbiology, College of Veterinary Medicine and Institute of Veterinary Science, Kangwon National University, Chuncheon 24341, Korea

Tel: $+82-33-250-8652$

Fax: $+82-33-254-5625$

E-mail: kwonhm@kangwon.ac.kr

ORCID:

Hyun-Woo Moon

https://orcid.org/0000-0002-4191-7590

Haan Woo Sung

https://orcid.org/0000-0001-7715-1390

Hyuk Moo Kwon

https://orcid.org/0000-0003-4953-8293

Conflict of Interest

The authors declare no conflicts of interest.

Received: April 19, 2019

Revised: July 11, 2019

Accepted: July 15, 2019

\section{Introduction}

Infectious bronchitis (IB) is an acute and highly contagious disease in chickens, causing respiratory stress and urogenital tract diseases [1]. IB virus (IBV), the etiologic agent of IB, is an enveloped, positive-sense, singlestranded, non-segmented RNA virus with a genome of approximately $27.6 \mathrm{~kb}$ [2,3]. IBV possesses at least 10 open-reading frames (ORFs): $5^{\prime}$ untranslated region (UTR)-1a-1b-S-3a-3b-E-M-5a-5b-N-3'UTR [4]. The replicase gene of IBV consists of ORF1a and ORF1b, which is translated to 2 polyproteins, ppla and pplab $[5,6]$. The replicase gene was elucidated to be a determinant of pathogenicity in IBV [7]. Four structural proteins are spike glycoprotein (S), small membrane protein (E), membrane glycoprotein (M), and nucleocapsid protein (N) [4]. The $\mathrm{S}$ glycoprotein is cleaved into $\mathrm{S} 1$ and $\mathrm{S} 2$ by cellular proteases and the $\mathrm{S} 1$ subunit produces serotype-specific and neutralizing antibodies [8-10]. Interactions between the membrane bilayer and the $\mathrm{E}$ and $\mathrm{M}$ proteins are important for virus budding and virus-like particles formation [11]. The $3 \mathrm{a}, 3 \mathrm{~b}, 5 \mathrm{a}$, and $5 \mathrm{~b}$ accessory proteins are not essential to viral replication $[12,13]$.

It is essential to know the antigenicity of the current IBVs in order to develop an effective vaccine, because the vaccine for IB prevention may not provide complete defense if the antigenicity is different. In Korea, IBV was first delineated in 1986 [14]. IB has been controlled by the use of live attenuated vaccine H120 strain and inactivated oil-emulsion vaccines containing both IBV KM91 and M41 strains [15]. Despite extensive vaccination, IB is still epidemic in Korea because of the frequent emergence of new variants [16-19]. Recombination and point mutation can lead to the emergence and evolution of new IBV variants [20]. Several studies on the molecular characterization of Korean IBVs have been reported [21-24]. However, most studies were mainly focused on partial sequences, including the S1 region. Because point mutation and recombination events were discovered to be distributed 
throughout the whole genome, investigating only a small part of the genome may result in misleading conclusions [25-29]. Therefore, it is essential to define the extensive part of the genome. Up to now, comprehensive genetic data on IBV strains circulating in Korea has been very limited [16,18].

The purpose of this study was to determine the genomic sequences of Korean IBV isolates K046-12 and K047-12 and to investigate their potential genetic origin and variation, providing IBV molecular epidemiology information and the genetic characteristics of Korean IBV isolates for the prevention of IB.

\section{Materials and Methods}

\section{Viral isolation and propagation}

IBV K046-12 strain was isolated from the trachea of a 30days-old broiler showing with inflammation in the trachea and ascites in broiler farm in 2012 in Cheorwon-gun, Gangwon province, Korea. IBV K047-12 strain was isolated from the cecal tonsil of a 6-weeks-old layer showing emaciation, inflammation in the trachea, thymic atrophy, renal enlargement and atrophy of systemic organs in Hy-line layer farm in
2012 in Pocheon-city, Gyeonggi province, Korea. These farms had a history of increased mortality. IBVs K046-12 and K047-12 were propagated in 9- to 11-day-old specific pathogen-free chicken embryos.

\section{Primer design}

Twenty-five primer pairs were made based on the published IBV genome sequence [28] and 2 primer pairs were designed using the primer walking method (Table 1). Eight other primers including K046-5'GSOP (TCTGCTCACTAAACACCACC), K046-5'GSIP (CTACAAACGTCGTATAGCCG), K046-3'GSOP (CTCAGATGAGGAGAGGAACA), K046-3'GSIP (GGTGATTCTGCACTTGGTGA), K047-5'GSOP (CCTACAACCGTCGTATAGTC), K047-5'GSIP (ACCTTGTGCGAGAACGTAGCGGA), K047-3'GSOP (GGGATTGACCT CAGATGAGGA), and K047-3'GSIP (GGGATTCAGCACTTGGAGAGA) were specifically made to amplify viral RNA 3'- and 5'-terminal end sequences.

Reverse transcription-polymerase chain reaction (RTPCR) and rapid amplification of cDNA ends (RACE)

For complete genome sequencing, viral RNAs were extracted

Table 1. Primers for the genome amplification and sequencing of infectious bronchitis virus K046-12 and K047-12 isolates

\begin{tabular}{|c|c|c|c|}
\hline Primer pairs & Size & "Upstream primer $\left(5^{\prime}-3^{\prime}\right)$ & Downstream primer $\left(5^{\prime}-3^{\prime}\right)$ \\
\hline $\mathrm{P} 1$ & 1623 & AGCGTTGGGCTACGTTCTC & CCAAATGCCCTCACCAAG \\
\hline $\mathrm{P} 2$ & 801 & GCGTACAATAGAGTGCGCAATC & GAGCAATTGTTCTACTGTGAGGTC \\
\hline P3 & 1052 & GGTTAGCATTGAGTGTTGTGGTG & GAGACATATGCTCATTTGCGG \\
\hline P4 & 1575 & GGCATTGGATGAGTTTAAAGAG & CGAACTTTAAGTGTCAGTGGCA \\
\hline P5 & 1186 & TGAAGTGGTAAAGGAAGATGTT & AAATCCTACACCAGTTTGCA \\
\hline P6 & 1116 & GGCAGGTTTTGTTATTATTTG & AAATACTTAAGACAACTGTCAGACA \\
\hline P7 & 1213 & TTTTTGATAAATGCAGATGCT & TAGTAAATACAGTGGTTGCATAAG \\
\hline P8 & 802 & AATGGTTATAAAGTTTCAAGGTGT & CAACTTCAAATCATGATTATTAGC \\
\hline P9 & 935 & GCTGTTGAGAAGTGCATTGTT & ACACATCTACTCCAAAACCAAG \\
\hline $\mathrm{P} 10$ & 1142 & TAATCAGGTGGGTGGTGTT & TCTTAAGTATATCATCACAATACTCAC \\
\hline P11 & 1030 & GCAAATTCAAAAATGCATGCTTAT & CAAATTTACATGGTGGGTCTAAGTC \\
\hline $\mathrm{P} 12$ & 1263 & CAGCGTAGAGTCTAAATGTTATTA & GCCCATTTTAGCCAACAT \\
\hline $\mathrm{P} 13$ & 821 & AATAAGGATTGGTACGACCC & ССТTCСТTAAACATACCTGCTT \\
\hline P14 & 1063 & GAACTTGGTGTTATTATGAATCAAGATA & CAACATTAGCAGATGTGGCTTG \\
\hline P15 & 1072 & GTACTAGCAGTGATGCTAC & TCAACATTTTCGCTACCTACA \\
\hline P16 & 845 & TAGTATCTAATGGTACTGTTTTTGGAATTT & TGGCAAGGCATTAATAGTACTAAAAAT \\
\hline P17 & 858 & AATTTCTTAAAGTTGATGATTGCACTC & TGCAAATTTTAAACAAACCTGTACCT \\
\hline P18 & 1090 & CGTGGTATACTTGTAGTCATGC & CTTTAGGGTTGCCTATATCATAG \\
\hline P19 & 1181 & CATATTGCAAATGAGGATGAAGT & ACATACAGATTCGCTCCATCT \\
\hline $\mathrm{P} 20$ & 792 & GGTGTCTACCACGTGTTATAAGC & GGCACACACATTGTAGTTTTAG \\
\hline $\mathrm{P} 21$ & 773 & CAAGTGGTATTATGATGAATGTGGC & AGTGACTTCCCCAACATCTCTAATC \\
\hline $\mathrm{P} 22$ & 1118 & AAGATGATAGTGCCAGAAGAAT & AACACTATGCCATTAGGTGC \\
\hline $\mathrm{P} 23$ & 748 & TTGTGGTAGTGGAAGACATGT & CCATTAAACAGACTTTTTAGGTC \\
\hline $\mathrm{P} 24$ & 1131 & GAATCTTCTTATTACACTACTTTTGA & ACTCTCTATAGCAAAATTACATTGT \\
\hline P25 & 1078 & TTAGACTCTTTAAGCGGTGTAG & GAATACTAGGGAGGTACACGC \\
\hline P15+ & 1072 & GTACTAGCAGTGGTGATGC & TCAACGTTTTCGCTACCCACA \\
\hline $\mathrm{P} 25+$ & 1141 & GTAGGTCTTGGTGGTCATTTA & AGTCCGACTTTCCAGATACTT \\
\hline
\end{tabular}


and purified with Viral Gen-spin Viral DNA/RNA Extraction kit (iNtRON, Korea) and stored at $-70^{\circ} \mathrm{C}$ until further use. RT-PCRs were performed with a One-Step RT-PCR kit (Qiagen, Germany) using respective primer pairs. Twenty-five overlapped polymerase chain reaction (PCR) fragments were amplified using specific primer pairs. The $5^{\prime}$ and $3^{\prime}$ end regions of the viral genomes were determined using the FirstChoice RLM-RACE kit (Ambion, USA) according to the manufacturer's instructions.

\section{Cloning and sequencing}

PCR products of the correct size were cut from agarose gel and purified using a MEGAquick-spin Fragment DNA Purification kit (iNtRON). The purified PCR products were then cloned into the pCR2.1-TOPO vector and transformed into the One-Shot TOP10 competent cells (Invitrogen, USA). Positive clones were extracted plasmid DNAs using DNAspin Plasmid DNA Purification Kit (iNtRON). Confirmation of clones including recombinant plasmid was carried out by restriction enzyme digestion. Plasmid DNAs were sequenced in both directions by fluorescence-based sequencing (Macrogen, Korea).

\section{Sequence and phylogenetic analysis}

The nearly complete genome sequences were assembled and analyzed using the Lasergene version 10 (DNASTAR, Inc., USA) computer program. These sequences were compared to each other and to the published IBV sequences by MegAlign Clustal W. Phylogenetic trees based on 1a, 1b, S, $\mathrm{S} 1, \mathrm{~S} 2,3 \mathrm{a}, 3 \mathrm{~b}, \mathrm{E}, \mathrm{M}, 5 \mathrm{a}, 5 \mathrm{~b}$, and N, and nearly complete genome sequences were generated by using the Lasergene software with bootstrap replicates for 1,000 replicates of original data. The sequence of IBV reference strains was retrieved from the GenBank database and accession numbers for the complete genomic sequences or nearly complete genomic sequences of 12 reference IBV strains and 2 reference human coronavirus strains used in this study are: H120 (FJ888351), IBVUkr27-11 (KJ135013), Arkansas vaccine (GQ 504721), Connecticut vaccine (KF696629), Massachusetts (GQ504724), SNU8067 (JQ977697), KM91 (JQ977698), GX-C (KC008600), Sczy3 (JF732903), SDZB0808 (KF853202), CK,CH,IBTZ,2012 (KF 663559), LX4 (AY338732), MERSCoV-human-1 (KF958702), and TOR2-SARS CoV (AY274119).

\section{Recombination analysis}

Putative recombinant sequences were detected by the soft

Table 2. Nucleotide and amino acid identities of different regions between Korean IBV K046-12 and other IBV strain genomes

\begin{tabular}{|c|c|c|c|c|c|c|c|c|c|c|c|c|c|}
\hline Strain & $\begin{array}{c}\text { Complete } \\
\text { genome }\end{array}$ & $1 \mathrm{a}$ & $1 b$ & $\mathrm{~S}$ & $\mathrm{~S} 1$ & S2 & $3 a$ & $3 b$ & $\mathrm{E}$ & M & $5 \mathrm{a}$ & $5 b$ & $\mathrm{~N}$ \\
\hline K047-12 & $89.0^{*}$ & $\begin{array}{c}85.3 \\
(87.1)\end{array}$ & $\begin{array}{c}93.9 \\
(97.1)\end{array}$ & $\begin{array}{c}88.1 \\
(87.8)\end{array}$ & $\begin{array}{c}80.4 \\
(78.1)\end{array}$ & $\begin{array}{c}94.7 \\
(96.2)\end{array}$ & $\begin{array}{r}97.7 \\
\mathbf{( 1 0 0 )}\end{array}$ & $\begin{array}{c}74.6 \\
(65.1)\end{array}$ & $\begin{array}{c}92.4 \\
(89.1)\end{array}$ & $\begin{array}{c}94.7 \\
(96.0)\end{array}$ & $\begin{array}{c}83.8 \\
(83.3)\end{array}$ & $\begin{array}{r}90.0 \\
(85.5)\end{array}$ & $\begin{array}{r}\mathbf{8 9 . 9} \\
(94.1)\end{array}$ \\
\hline SNU8067 & 95.1 & $\begin{array}{c}95.9 \\
(96.6)\end{array}$ & $\begin{array}{c}96.3 \\
(97.7)\end{array}$ & $\begin{array}{c}89.7 \\
(88.5)\end{array}$ & $\begin{array}{c}81.1 \\
(78.0)\end{array}$ & $\begin{array}{c}96.9 \\
(97.0)\end{array}$ & $\begin{array}{c}\mathbf{9 8 . 9} \\
(98.3)\end{array}$ & $\begin{array}{c}94.9 \\
(93.8)\end{array}$ & $\begin{array}{c}95.4 \\
(93.6)\end{array}$ & $\begin{array}{c}93.1 \\
(96.9)\end{array}$ & $\begin{array}{c}97.0 \\
(98.5)\end{array}$ & $\begin{array}{c}95.6 \\
(90.4)\end{array}$ & $\begin{array}{l}94.6 \\
(\mathbf{9 6 . 8})\end{array}$ \\
\hline KM91 & 94.3 & $\begin{array}{l}94.8 \\
(95.6)\end{array}$ & $\begin{array}{c}95.3 \\
(97.0)\end{array}$ & $\begin{array}{c}90.9 \\
(90.0)\end{array}$ & $\begin{array}{c}83.8 \\
(82.3)\end{array}$ & $\begin{array}{l}96.8 \\
(96.7)\end{array}$ & $\begin{array}{c}75.5 \\
(61.2)\end{array}$ & $\begin{array}{l}81.5 \\
(74.6)\end{array}$ & $\begin{array}{c}97.0 \\
(96.4)\end{array}$ & $\begin{array}{c}96.0 \\
(98.2)\end{array}$ & $\begin{array}{c}96.5 \\
\mathbf{( 9 8 . 5 )}\end{array}$ & $\begin{array}{l}95.6 \\
(91.6)\end{array}$ & $\begin{array}{l}\mathbf{9 4 . 7} \\
(95.6)\end{array}$ \\
\hline Sczy3 & 87.3 & $\begin{array}{c}85.3 \\
(87.1)\end{array}$ & $\begin{array}{c}90.3 \\
(95.8)\end{array}$ & $\begin{array}{c}86.5 \\
(87.4)\end{array}$ & $\begin{array}{c}77.8 \\
(77.7)\end{array}$ & $\begin{array}{l}93.9 \\
(95.6)\end{array}$ & $\begin{array}{c}77.0 \\
(69.0)\end{array}$ & $\begin{array}{c}75.1 \\
(65.1)\end{array}$ & $\begin{array}{c}85.6 \\
(83.5)\end{array}$ & $\begin{array}{c}89.2 \\
(93.4)\end{array}$ & $\begin{array}{c}85.4 \\
(80.3)\end{array}$ & $\begin{array}{c}94.8 \\
(89.2)\end{array}$ & $\begin{array}{c}90.3 \\
(93.9)\end{array}$ \\
\hline LX4 & 86.8 & $\begin{array}{r}84.9 \\
(86.5)\end{array}$ & $\begin{array}{c}90.2 \\
(95.7)\end{array}$ & $\begin{array}{c}84.4 \\
(85.4)\end{array}$ & $\begin{array}{c}78.1 \\
(76.2)\end{array}$ & $\begin{array}{c}89.7 \\
(93.0)\end{array}$ & $\begin{array}{c}78.7 \\
(70.7)\end{array}$ & $\begin{array}{c}74.5 \\
(65.6)\end{array}$ & $\begin{array}{c}88.8 \\
(84.5)\end{array}$ & $\begin{array}{c}90.3 \\
(91.6)\end{array}$ & $\begin{array}{c}81.8 \\
\mathbf{( 7 4 . 2})\end{array}$ & $\begin{array}{c}91.2 \\
(91.6)\end{array}$ & $\begin{array}{c}90.1 \\
(93.7)\end{array}$ \\
\hline SDZB0808 & 87.2 & $\begin{array}{c}85.2 \\
(87.0)\end{array}$ & $\begin{array}{c}90.2 \\
(96.1)\end{array}$ & $\begin{array}{c}86.3 \\
(86.8)\end{array}$ & $\begin{array}{c}77.6 \\
(76.4)\end{array}$ & $\begin{array}{l}93.7 \\
(95.4)\end{array}$ & $\begin{array}{c}78.2 \\
(70.7)\end{array}$ & $\begin{array}{c}75.1 \\
(\mathbf{6 3 . 5})\end{array}$ & $\begin{array}{c}85.6 \\
(83.5)\end{array}$ & $\begin{array}{c}89.7 \\
(93.8)\end{array}$ & $\begin{array}{c}83.8 \\
(84.8)\end{array}$ & $\begin{array}{c}92.0 \\
(89.2)\end{array}$ & $\begin{array}{c}90.9 \\
(94.9)\end{array}$ \\
\hline $\begin{array}{l}\text { CK, CH, IBTZ, } \\
2012\end{array}$ & 85.3 & $\begin{array}{c}85.5 \\
(87.5)\end{array}$ & $\begin{array}{c}\mathbf{8 9 . 9} \\
(95.8)\end{array}$ & $\begin{array}{c}70.7 \\
(66.7)\end{array}$ & $\begin{array}{c}65.1 \\
(\mathbf{5 8 . 3})\end{array}$ & $\begin{array}{c}75.6 \\
(73.7)\end{array}$ & $\begin{array}{c}79.3 \\
(70.7)\end{array}$ & $\begin{array}{c}82.5 \\
(74.6)\end{array}$ & $\begin{array}{c}90.1 \\
(87.5)\end{array}$ & $\begin{array}{c}88.3 \\
(91.2)\end{array}$ & $\begin{array}{c}\mathbf{8 1 . 3} \\
(77.3)\end{array}$ & $\begin{array}{c}92.0 \\
(86.7)\end{array}$ & $\begin{array}{c}90.7 \\
(94.4)\end{array}$ \\
\hline GX-C & 88.7 & $\begin{array}{l}88.8 \\
(90.3)\end{array}$ & $\begin{array}{c}90.6 \\
\mathbf{( 9 5 . 5 )}\end{array}$ & $\begin{array}{c}83.0 \\
(83.6)\end{array}$ & $\begin{array}{c}80.8 \\
(78.1)\end{array}$ & $\begin{array}{c}84.3 \\
(87.8)\end{array}$ & $\begin{array}{c}81.0 \\
(79.3)\end{array}$ & $\begin{array}{c}79.4 \\
(68.3)\end{array}$ & $\begin{array}{c}91.1 \\
(89.9)\end{array}$ & $\begin{array}{c}88.9 \\
\mathbf{( 9 1 . 2 )}\end{array}$ & $\begin{array}{c}82.8 \\
(80.3)\end{array}$ & $\begin{array}{c}92.3 \\
(87.8)\end{array}$ & $\begin{array}{r}\mathbf{8 9 . 9} \\
(92.7)\end{array}$ \\
\hline $\begin{array}{l}\text { Connecticut } \\
\text { vaccine }\end{array}$ & 92.3 & $\begin{array}{c}92.7 \\
(93.6)\end{array}$ & $\begin{array}{c}93.0 \\
(97.0)\end{array}$ & $\begin{array}{c}89.9 \\
(90.2)\end{array}$ & $\begin{array}{c}94.0 \\
(90.7)\end{array}$ & $\begin{array}{c}86.5 \\
(89.7)\end{array}$ & $\begin{array}{c}94.3 \\
(93.1)\end{array}$ & $\begin{array}{c}91.3 \\
(89.2)\end{array}$ & $\begin{array}{c}88.6 \\
(84.3)\end{array}$ & $\begin{array}{c}91.4 \\
(93.3)\end{array}$ & $\begin{array}{c}\mathbf{9 7 . 0} \\
(97.0)\end{array}$ & $\begin{array}{c}96.0 \\
(92.8)\end{array}$ & $\begin{array}{c}93.3 \\
(95.6)\end{array}$ \\
\hline H120 & 91.5 & $\begin{array}{l}91.0 \\
(91.6)\end{array}$ & $\begin{array}{c}93.1 \\
(97.4)\end{array}$ & $\begin{array}{c}91.2 \\
(92.7)\end{array}$ & $\begin{array}{c}98.4 \\
(98.1)\end{array}$ & $\begin{array}{c}85.4 \\
(88.1)\end{array}$ & $\begin{array}{c}81.0 \\
(79.3)\end{array}$ & $\begin{array}{c}85.1 \\
(70.8)\end{array}$ & $\begin{array}{c}86.7 \\
(84.5)\end{array}$ & $\begin{array}{c}88.6 \\
(91.6)\end{array}$ & $\begin{array}{c}93.4 \\
(93.9)\end{array}$ & $\begin{array}{c}94.0 \\
(89.2)\end{array}$ & $\begin{array}{l}90.6 \\
\mathbf{( 9 2 . 4 )}\end{array}$ \\
\hline IBVUkr27-11 & 90.1 & $\begin{array}{c}90.7 \\
(91.5)\end{array}$ & $\begin{array}{c}91.9 \\
(96.3)\end{array}$ & $\begin{array}{c}84.1 \\
(85.1)\end{array}$ & $\begin{array}{c}83.2 \\
(80.8)\end{array}$ & $\begin{array}{c}85.2 \\
(88.9)\end{array}$ & $\begin{array}{c}89.1 \\
(84.5)\end{array}$ & $\begin{array}{c}91.3 \\
(87.7)\end{array}$ & $\begin{array}{c}88.1 \\
(85.3)\end{array}$ & $\begin{array}{c}89.7 \\
(92.5)\end{array}$ & $\begin{array}{c}86.9 \\
(87.9)\end{array}$ & $\begin{array}{c}95.6 \\
\mathbf{( 9 5 . 2 )}\end{array}$ & $\begin{array}{c}91.2 \\
(93.2)\end{array}$ \\
\hline Massachusetts & 90.8 & $\begin{array}{c}90.4 \\
(91.9)\end{array}$ & $\begin{array}{c}92.2 \\
(96.6)\end{array}$ & $\begin{array}{l}90.6 \\
(91.7)\end{array}$ & $\begin{array}{c}96.6 \\
(95.7)\end{array}$ & $\begin{array}{c}85.6 \\
(88.3)\end{array}$ & $\begin{array}{c}82.8 \\
(77.6)\end{array}$ & $\begin{array}{c}84.6 \\
(70.8)\end{array}$ & $\begin{array}{c}87.3 \\
(87.3)\end{array}$ & $\begin{array}{c}88.6 \\
(92.0)\end{array}$ & $\begin{array}{c}88.9 \\
(86.4)\end{array}$ & $\begin{array}{c}95.6 \\
(92.8)\end{array}$ & $\begin{array}{c}90.7 \\
(93.9)\end{array}$ \\
\hline Arkansas vaccine & 91.1 & $\begin{array}{c}91.8 \\
(92.2)\end{array}$ & $\begin{array}{c}93.0 \\
(96.5)\end{array}$ & $\begin{array}{c}83.7 \\
(83.5)\end{array}$ & $\begin{array}{c}80.8 \\
(76.9)\end{array}$ & $\begin{array}{c}86.2 \\
(88.9)\end{array}$ & $\begin{array}{c}89.7 \\
(86.2)\end{array}$ & $\begin{array}{c}91.3 \\
(87.7)\end{array}$ & $\begin{array}{c}88.6 \\
(85.2)\end{array}$ & $\begin{array}{c}91.2 \\
(93.3)\end{array}$ & $\begin{array}{c}\mathbf{9 7 . 0} \\
(97.0)\end{array}$ & $\begin{array}{c}95.2 \\
(90.4)\end{array}$ & $\begin{array}{c}92.9 \\
(94.9)\end{array}$ \\
\hline
\end{tabular}

IBV, infectious bronchitis virus.

${ }^{*}$ Sequences with the higher or lowest identity with K046-12 at the nucleotide and amino acid level shown in bold. Parentheses indicate amino acid sequence identity. 
package of Simplot (USA) [30]. The IBV nucleotide sequences from the nearly complete genome based on the multiple alignment data were introduced into similarity plots with SimPlot version 3.5.1. The nucleotide identity was calculated using the Kimura 2-parameter method with a transitiontransversion ratio of 2 in each window of $200 \mathrm{bp}$, and the window was successively furthered along the alignment using a 20 bp increment.

\section{Results}

\section{Sequence determination and analysis}

The nucleotide sequence data determined in this study have been deposited in the GenBank database under the accession numbers MK618758 for K046-12 and MK618759 for K047-12. The nearly complete genome of K046-12 consists of 26760 nucleotides (nt). The nucleotide sequence length of the different ORFs $1 \mathrm{a}, 1 \mathrm{~b}, \mathrm{~S}, 3 \mathrm{a}, 3 \mathrm{~b}, \mathrm{E}, \mathrm{M}, 5 \mathrm{a}, 5 \mathrm{~b}$, and $\mathrm{N}$ were 11859, 7959, 3489, 174, 195, 333, 681, 198, 249, and $1230 \mathrm{nt}$ long, respectively. The nearly complete genome of K047-12 consists of $27698 \mathrm{nt}$, including poly (A) tail and 5' (525 nt) and 3' (541 nt) UTRs. The nucleotide sequence length of the different ORFs 1a, 1b, S, 3a, 3b, E, M, 5a, 5b, and $\mathrm{N}$ were 11856, 7959, 3489, 174, 189, 330, 681, 198, 249, and $1230 \mathrm{nt}$ long, respectively. Sequence comparison analysis showed that the genomic nucleotide sequence identity between K046-12 and other IBV strains ranged from 85.3\% (CK, CH, IBTZ, 2012) to 95.1\% (SNU8067), and the genomic nucleotide sequence identity between K047-12 and other IBV strains ranged from $86.5 \%$ (IBVUkr27-11) to $94.8 \%$ (SDZB0808 [QX-like]).

The nucleotide sequence identity between the $1 \mathrm{a}, 1 \mathrm{~b}, \mathrm{~S}$, $\mathrm{S} 1, \mathrm{~S} 2,3 \mathrm{a}, 3 \mathrm{~b}, \mathrm{E}, \mathrm{M}, 5 \mathrm{a}, 5 \mathrm{~b}$, and $\mathrm{N}$ between K046-12 and other IBVs was $84.9 \%$ (LX4) to $95.9 \%$ (SNU8067), $89.9 \%$ (CK, CH, IBTZ, 2012) to 96.3\% (SNU8067), 70.7\% (CK, $\mathrm{CH}, \mathrm{IBTZ}, 2012)$ to $91.2 \%$ (H120), 65.1\% (CK, CH, IBTZ, 2012 ) to $98.4 \%$ (H120), $75.6 \%$ (CK, CH, IBTZ, 2012) to 96.9\% (SNU0867), 75.5\% (KM91) to 98.9\% (SNU8067), $74.5 \%$ (LX4) to $94.9 \%$ (SNU8067), 85.6\% (Sczy3 and SDZB0808) to $97.0 \%$ (KM91), 88.3\% (CK, CH, IBTZ, 2012 ) to $96.0 \%$ (KM91), $81.3 \%(\mathrm{CK}, \mathrm{CH}, \mathrm{IBTZ}, 2012)$ to 97.0\% (SNU8067, Connecticut vaccine, and Arkansas vaccine), $90.0 \%$ (K047-12) to $96.0 \%$ (Connecticut vaccine), and $89.9 \%$ (K047-12 and GX-C) to $94.7 \%$ (KM91), respectively

Table 3. Nucleotide and amino acid identities of different regions between Korean IBV K047-12 and other IBV strain genomes

\begin{tabular}{|c|c|c|c|c|c|c|c|c|c|c|c|c|c|}
\hline Strain & $\begin{array}{c}\text { Complete } \\
\text { genome }\end{array}$ & 1a & $1 b$ & $\mathrm{~S}$ & S1 & $\mathrm{S} 2$ & $3 a$ & $3 b$ & E & M & $5 a$ & $5 b$ & $\mathrm{~N}$ \\
\hline K046-12 & $89.0^{*}$ & $\begin{array}{c}85.3 \\
(87.1)\end{array}$ & $\begin{array}{l}93.9 \\
(97.1)\end{array}$ & $\begin{array}{c}88.1 \\
(87.8)\end{array}$ & $\begin{array}{c}80.4 \\
(78.1)\end{array}$ & $\begin{array}{c}94.7 \\
(96.2)\end{array}$ & $\begin{array}{l}97.7 \\
(100)\end{array}$ & $\begin{array}{c}74.6 \\
(65.1)\end{array}$ & $\begin{array}{c}92.4 \\
(89.1)\end{array}$ & $\begin{array}{c}94.7 \\
(96.0)\end{array}$ & $\begin{array}{c}83.8 \\
(83.3)\end{array}$ & $\begin{array}{c}90.0 \\
(85.5)\end{array}$ & $\begin{array}{c}89.9 \\
(94.1)\end{array}$ \\
\hline SNU8067 & 88.4 & $\begin{array}{c}85.3 \\
(87.4)\end{array}$ & $\begin{array}{l}92.9 \\
(97.2)\end{array}$ & $\begin{array}{c}87.6 \\
(87.6)\end{array}$ & $\begin{array}{c}80.3 \\
(77.8)\end{array}$ & $\begin{array}{l}94.0 \\
(95.9)\end{array}$ & $\begin{array}{c}97.7 \\
(98.3)\end{array}$ & $\begin{array}{c}75.1 \\
(65.1)\end{array}$ & $\begin{array}{l}90.8 \\
(88.1)\end{array}$ & $\begin{array}{l}94.0 \\
(93.8)\end{array}$ & $\begin{array}{c}83.8 \\
(83.3)\end{array}$ & $\begin{array}{c}89.2 \\
(85.5)\end{array}$ & $\begin{array}{c}88.8 \\
(93.7)\end{array}$ \\
\hline KM91 & 88.4 & $\begin{array}{c}85.2 \\
\mathbf{( 8 7 . 0 )}\end{array}$ & $\begin{array}{c}92.4 \\
(96.8)\end{array}$ & $\begin{array}{c}91.4 \\
(92.0)\end{array}$ & $\begin{array}{c}88.1 \\
(87.1)\end{array}$ & $\begin{array}{c}94.4 \\
(96.2)\end{array}$ & $\begin{array}{c}76.2 \\
(61.2)\end{array}$ & $\begin{array}{c}77.6 \\
(67.7)\end{array}$ & $\begin{array}{l}\mathbf{9 2 . 7} \\
(91.8)\end{array}$ & $\begin{array}{c}95.7 \\
(97.8)\end{array}$ & $\begin{array}{c}83.3 \\
(81.8)\end{array}$ & $\begin{array}{c}88.8 \\
(84.3)\end{array}$ & $\begin{array}{c}87.3 \\
(92.0)\end{array}$ \\
\hline Sczy3 & 94.2 & $\begin{array}{c}95.9 \\
(96.1)\end{array}$ & $\begin{array}{c}93.2 \\
(97.1)\end{array}$ & $\begin{array}{c}95.9 \\
(\mathbf{9 6 . 2})\end{array}$ & $\begin{array}{c}94.3 \\
\mathbf{( 9 3 . 7 )}\end{array}$ & $\begin{array}{c}97.0 \\
(98.1)\end{array}$ & $\begin{array}{c}78.2 \\
(69.0)\end{array}$ & $\begin{array}{c}99.5 \\
(98.4)\end{array}$ & $\begin{array}{c}92.4 \\
(92.7)\end{array}$ & $\begin{array}{c}87.9 \\
(90.3)\end{array}$ & $\begin{array}{c}87.9 \\
(87.9)\end{array}$ & $\begin{array}{c}89.6 \\
(85.5)\end{array}$ & $\begin{array}{c}93.3 \\
(95.9)\end{array}$ \\
\hline LX4 & 91.0 & $\begin{array}{c}89.1 \\
(89.4)\end{array}$ & $\begin{array}{c}92.7 \\
(96.6)\end{array}$ & $\begin{array}{l}92.6 \\
(93.1)\end{array}$ & $\begin{array}{c}93.2 \\
(91.2)\end{array}$ & $\begin{array}{c}91.9 \\
(94.5)\end{array}$ & $\begin{array}{c}79.9 \\
(70.7)\end{array}$ & $\begin{array}{c}91.5 \\
(84.1)\end{array}$ & $\begin{array}{c}89.6 \\
(87.2)\end{array}$ & $\begin{array}{c}88.8 \\
(88.5)\end{array}$ & $\begin{array}{c}85.9 \\
(83.3)\end{array}$ & $\begin{array}{c}94.0 \\
(\mathbf{9 2 . 8})\end{array}$ & $\begin{array}{c}94.2 \\
(96.3)\end{array}$ \\
\hline SDZB0808 & 94.8 & $\begin{array}{l}95.8 \\
(95.9)\end{array}$ & $\begin{array}{c}94.8 \\
(97.8)\end{array}$ & $\begin{array}{c}96.1 \\
(96.0)\end{array}$ & $\begin{array}{c}94.8 \\
(93.5)\end{array}$ & $\begin{array}{c}97.0 \\
(97.9)\end{array}$ & $\begin{array}{c}79.3 \\
(70.7)\end{array}$ & $\begin{array}{c}98.4 \\
(96.8)\end{array}$ & $\begin{array}{c}92.4 \\
\mathbf{( 9 2 . 7 )}\end{array}$ & $\begin{array}{c}87.9 \\
(90.7)\end{array}$ & $\begin{array}{c}95.5 \\
(95.5)\end{array}$ & $\begin{array}{c}96.4 \\
(91.6)\end{array}$ & $\begin{array}{c}93.7 \\
(96.6)\end{array}$ \\
\hline $\begin{array}{l}\text { CK, CH, IBTZ, } \\
2012\end{array}$ & 91.1 & $\begin{array}{c}96.1 \\
(96.2)\end{array}$ & $\begin{array}{l}93.3 \\
(97.1)\end{array}$ & $\begin{array}{c}71.1 \\
(67.4)\end{array}$ & $\begin{array}{c}65.7 \\
(58.8)\end{array}$ & $\begin{array}{c}75.9 \\
(\mathbf{7 4 . 5})\end{array}$ & $\begin{array}{c}78.7 \\
(70.7)\end{array}$ & $\begin{array}{c}80.3 \\
(66.1)\end{array}$ & $\begin{array}{c}85.1 \\
(83.5)\end{array}$ & $\begin{array}{c}88.8 \\
(91.2)\end{array}$ & $\begin{array}{c}85.4 \\
(83.3)\end{array}$ & $\begin{array}{c}89.2 \\
(84.3)\end{array}$ & $\begin{array}{l}94.7 \\
(96.8)\end{array}$ \\
\hline GX-C & 87.4 & $\begin{array}{c}87.1 \\
(88.7)\end{array}$ & $\begin{array}{c}90.0 \\
(95.7)\end{array}$ & $\begin{array}{c}82.7 \\
(83.6)\end{array}$ & $\begin{array}{c}82.1 \\
(79.9)\end{array}$ & $\begin{array}{c}83.8 \\
(86.5)\end{array}$ & $\begin{array}{c}81.0 \\
(79.3)\end{array}$ & $\begin{array}{c}79.9 \\
(67.7)\end{array}$ & $\begin{array}{c}87.5 \\
(87.2)\end{array}$ & $\begin{array}{c}88.8 \\
(88.9)\end{array}$ & $\begin{array}{c}84.3 \\
(83.3)\end{array}$ & $\begin{array}{c}\mathbf{8 7 . 0} \\
(81.7)\end{array}$ & $\begin{array}{c}89.8 \\
(93.2)\end{array}$ \\
\hline $\begin{array}{l}\text { Connecticut } \\
\text { vaccine }\end{array}$ & 87.0 & $\begin{array}{c}85.3 \\
(87.3)\end{array}$ & $\begin{array}{c}90.8 \\
(96.2)\end{array}$ & $\begin{array}{c}83.2 \\
(83.9)\end{array}$ & $\begin{array}{c}78.9 \\
(76.8)\end{array}$ & $\begin{array}{c}87.0 \\
(89.9)\end{array}$ & $\begin{array}{c}94.3 \\
(93.1)\end{array}$ & $\begin{array}{c}74.1 \\
(63.5)\end{array}$ & $\begin{array}{c}88.2 \\
(86.0)\end{array}$ & $\begin{array}{c}92.7 \\
(93.3)\end{array}$ & $\begin{array}{c}85.4 \\
(83.3)\end{array}$ & $\begin{array}{c}89.6 \\
(86.7)\end{array}$ & $\begin{array}{c}88.0 \\
(92.4)\end{array}$ \\
\hline H120 & 87.2 & $\begin{array}{c}\mathbf{8 4 . 9} \\
(87.1)\end{array}$ & $\begin{array}{c}91.3 \\
(96.6)\end{array}$ & $\begin{array}{c}83.0 \\
(83.4)\end{array}$ & $\begin{array}{c}79.5 \\
(77.3)\end{array}$ & $\begin{array}{c}86.3 \\
(88.6)\end{array}$ & $\begin{array}{c}81.6 \\
(79.3)\end{array}$ & $\begin{array}{c}79.4 \\
(66.7)\end{array}$ & $\begin{array}{c}87.8 \\
(87.2)\end{array}$ & $\begin{array}{c}88.8 \\
\mathbf{( 9 0 . 3 )}\end{array}$ & $\begin{array}{c}87.9 \\
(87.9)\end{array}$ & $\begin{array}{c}88.8 \\
(85.5)\end{array}$ & $\begin{array}{c}88.0 \\
\mathbf{( 9 1 . 0 )}\end{array}$ \\
\hline IBVUkr27-11 & 86.5 & $\begin{array}{c}84.9 \\
(87.0)\end{array}$ & $\begin{array}{c}90.3 \\
\mathbf{( 9 5 . 7 )}\end{array}$ & $\begin{array}{c}82.6 \\
(84.9)\end{array}$ & $\begin{array}{c}79.2 \\
(78.7)\end{array}$ & $\begin{array}{c}85.7 \\
(90.2)\end{array}$ & $\begin{array}{c}87.9 \\
(84.5)\end{array}$ & $\begin{array}{c}74.6 \\
(63.5)\end{array}$ & $\begin{array}{c}88.3 \\
(88.3)\end{array}$ & $\begin{array}{c}89.9 \\
(91.2)\end{array}$ & $\begin{array}{c}88.4 \\
(89.4)\end{array}$ & $\begin{array}{c}89.2 \\
(86.7)\end{array}$ & $\begin{array}{c}\mathbf{8 7 . 0} \\
(91.5)\end{array}$ \\
\hline Massachusetts & 86.9 & $\begin{array}{c}85.5 \\
(87.2)\end{array}$ & $\begin{array}{c}90.3 \\
(95.8)\end{array}$ & $\begin{array}{c}82.9 \\
(83.0)\end{array}$ & $\begin{array}{c}79.3 \\
(76.8)\end{array}$ & $\begin{array}{c}86.3 \\
(88.4)\end{array}$ & $\begin{array}{c}82.2 \\
(77.6)\end{array}$ & $\begin{array}{c}79.4 \\
(68.3)\end{array}$ & $\begin{array}{c}88.4 \\
(89.9)\end{array}$ & $\begin{array}{c}88.3 \\
(90.7)\end{array}$ & $\begin{array}{c}82.3 \\
(78.8)\end{array}$ & $\begin{array}{c}87.1 \\
\mathbf{( 8 0 . 7 )}\end{array}$ & $\begin{array}{c}87.5 \\
\mathbf{( 9 1 . 0 )}\end{array}$ \\
\hline Arkansas vaccine & 86.9 & $\begin{array}{c}85.2 \\
(87.1)\end{array}$ & $\begin{array}{c}91.1 \\
(96.2)\end{array}$ & $\begin{array}{c}83.2 \\
(84.0)\end{array}$ & $\begin{array}{c}78.8 \\
(77.2)\end{array}$ & $\begin{array}{c}87.1 \\
(89.9)\end{array}$ & $\begin{array}{c}88.5 \\
(86.2)\end{array}$ & $\begin{array}{c}74.6 \\
(61.9)\end{array}$ & $\begin{array}{c}87.9 \\
(85.0)\end{array}$ & $\begin{array}{c}92.6 \\
(93.3)\end{array}$ & $\begin{array}{c}85.4 \\
(83.3)\end{array}$ & $\begin{array}{c}88.8 \\
(84.3)\end{array}$ & $\begin{array}{c}87.8 \\
(92.2)\end{array}$ \\
\hline
\end{tabular}

IBV, infectious bronchitis virus.

${ }^{*}$ Sequences with the higher or lowest identity with K046-12 at the nucleotide and amino acid level shown in bold. Parentheses indicate amino acid sequence identity. 
(Table 2). The nucleotide sequence identity between the $1 \mathrm{a}$, 1b, S, S1, S2, 3a, 3b, E, M, 5a, 5b, and N between K047-12 and other IBVs were $84.9 \%$ (H120 and IBVUkr27-11) to 96.1\% (CK, CH, IBTZ, 2012), 90.0\% (GX-C) to $94.8 \%$ (SDZB0808), 71.1\% (CK, CH, IBTZ, 2012) to $96.1 \%$ (SDZB0808), 65.7\% (CK, CH, IBTZ, 2012) to $94.8 \%$

(A)

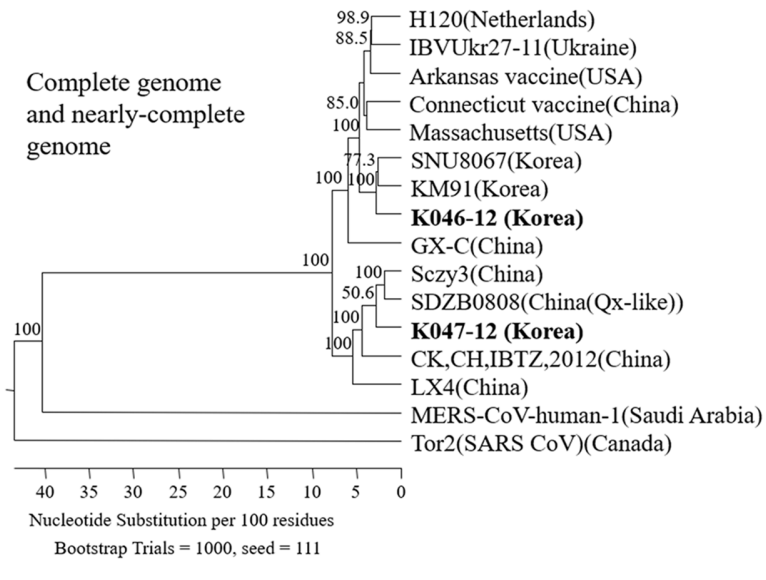

(C)

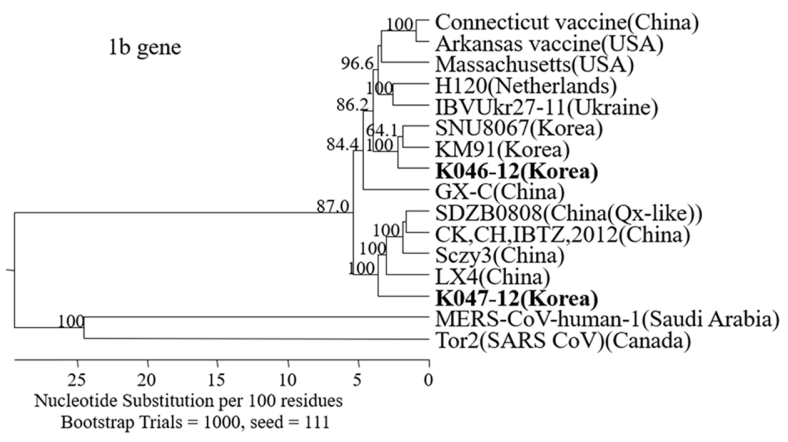

(E)

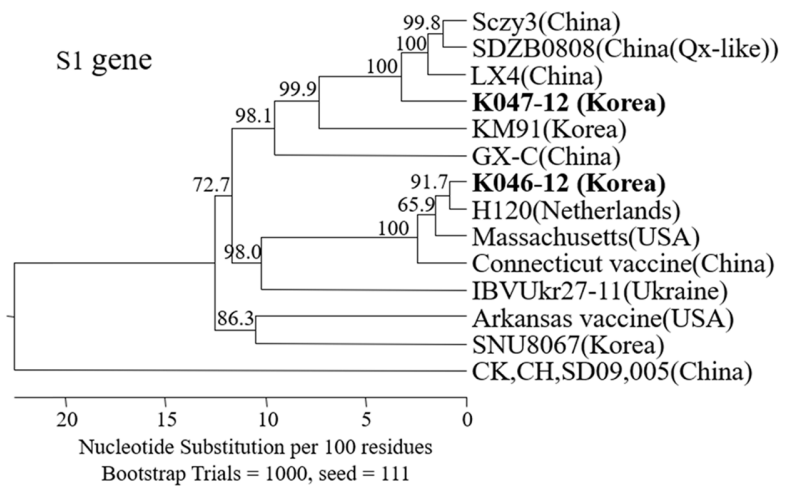

(SDZB0808), 75.9\% (CK, CH, IBTZ, 2012) to 97.0\% (Sczy3 and SDZB0808), 76.2\% (KM91) to 97.7\% (K046-12 and SNU8067), 74.1\% (Connecticut vaccine) to $99.5 \%$ (Sczy3), $85.1 \%$ (CK, CH, IBTZ, 2012) to 92.7\% (KM91), 87.9\% (Sczy3 and SDZB 0808) to 95.7\% (KM91), 82.3\% (Massachusetts) to $95.5 \%$ (SDZB0808), $87.0 \%$ (GX-C) to $96.4 \%$

(B)

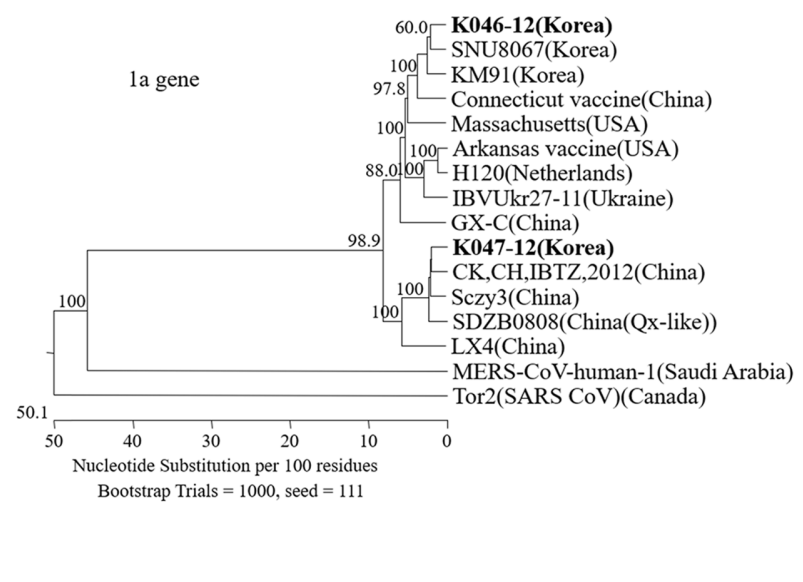

(D)

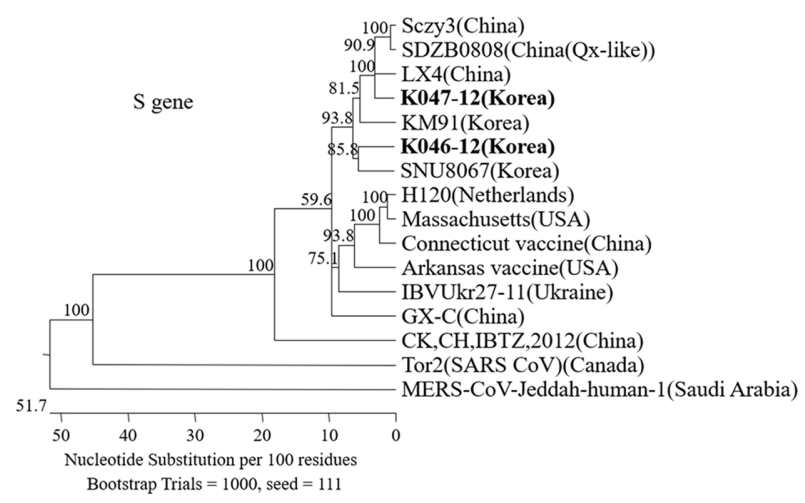

(F)

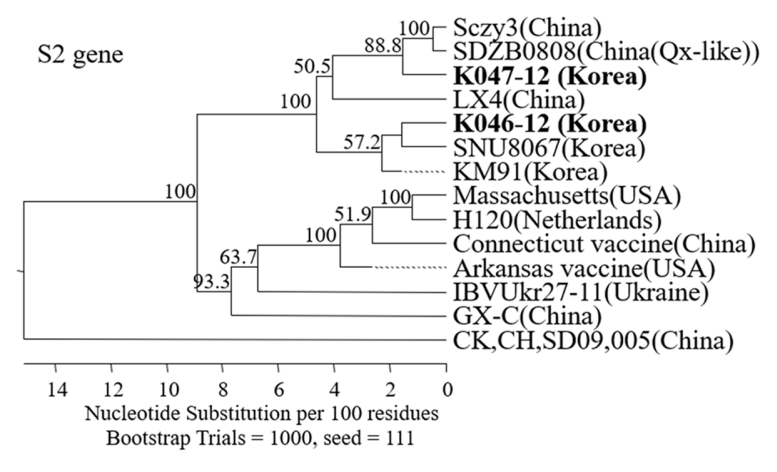

Fig. 1. Phylogenetic trees generated by neighbor-joining method with 1,000 bootstrap replicates by means of Lasergene software based on complete and nearly-complete genome (A), and different regions of genome (B-M). The length of each pair of branches represents the distance between sequence pairs, while the units at the bottom of each tree indicate the number of nucleotide substitution events. A dotted line on a tree indicates a negative branch length and bootstrap value $>50 \%$ are indicated for the major nodes. Putative recombinant IBV isolates (K046-12 and K047-12) are shown in bold. IBV, infectious bronchitis virus. 
(G)

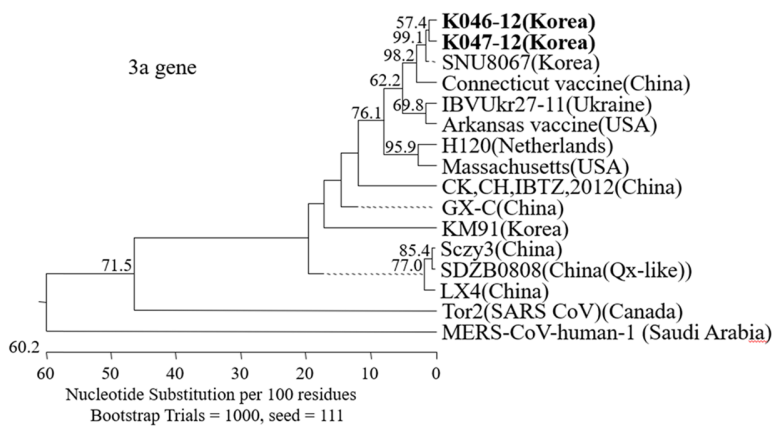

(I)

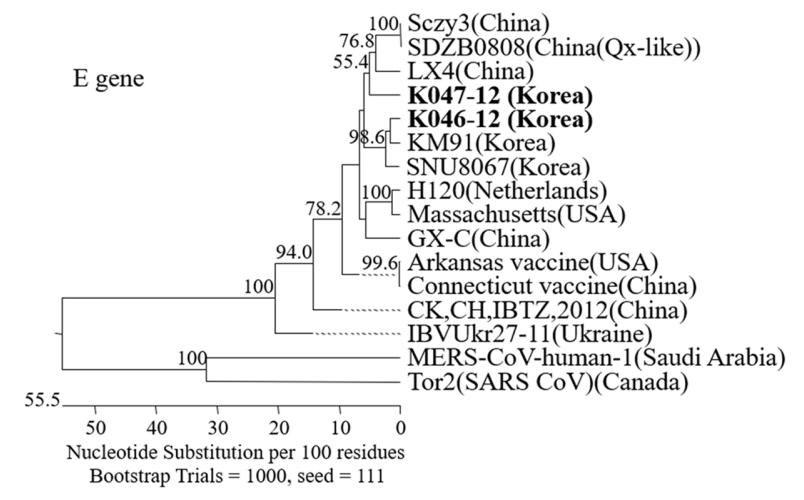

(K)

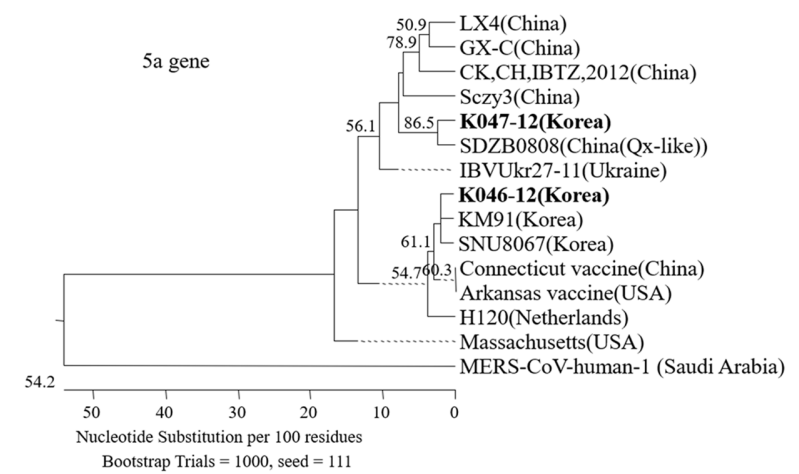

(M)

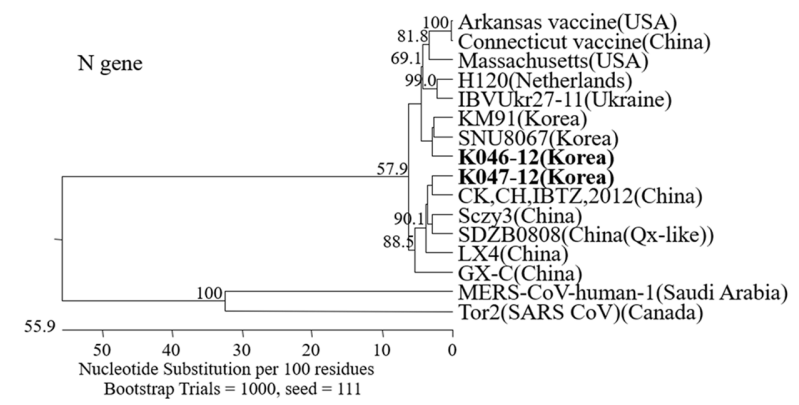

(H)
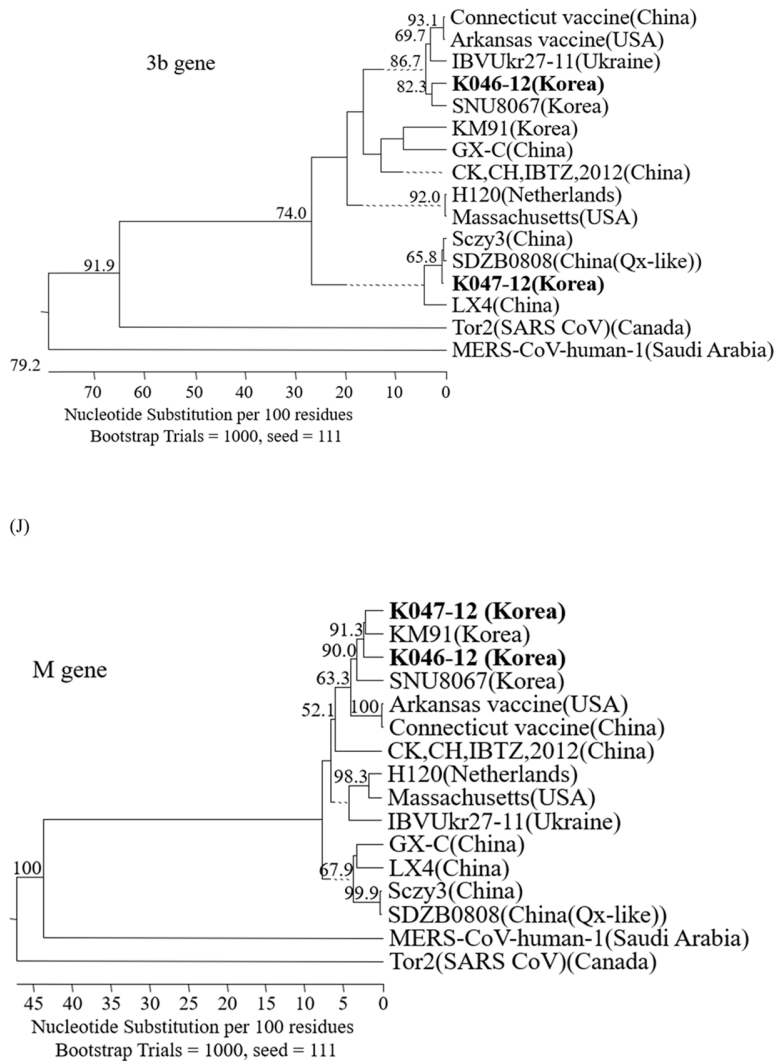

(L)

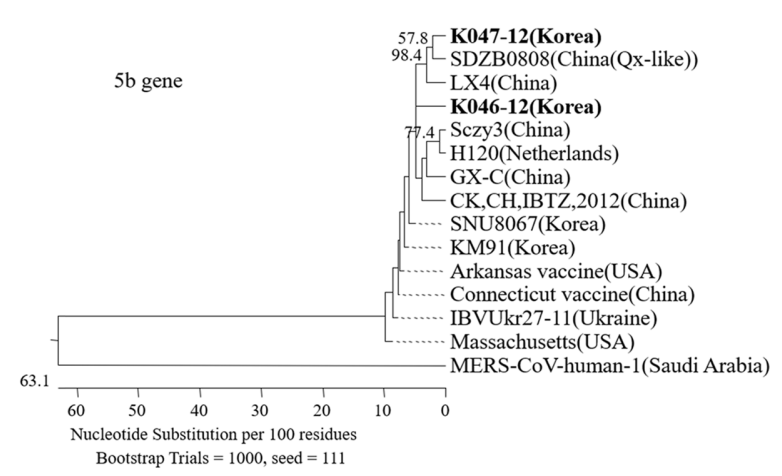

Fig. 1. continued 

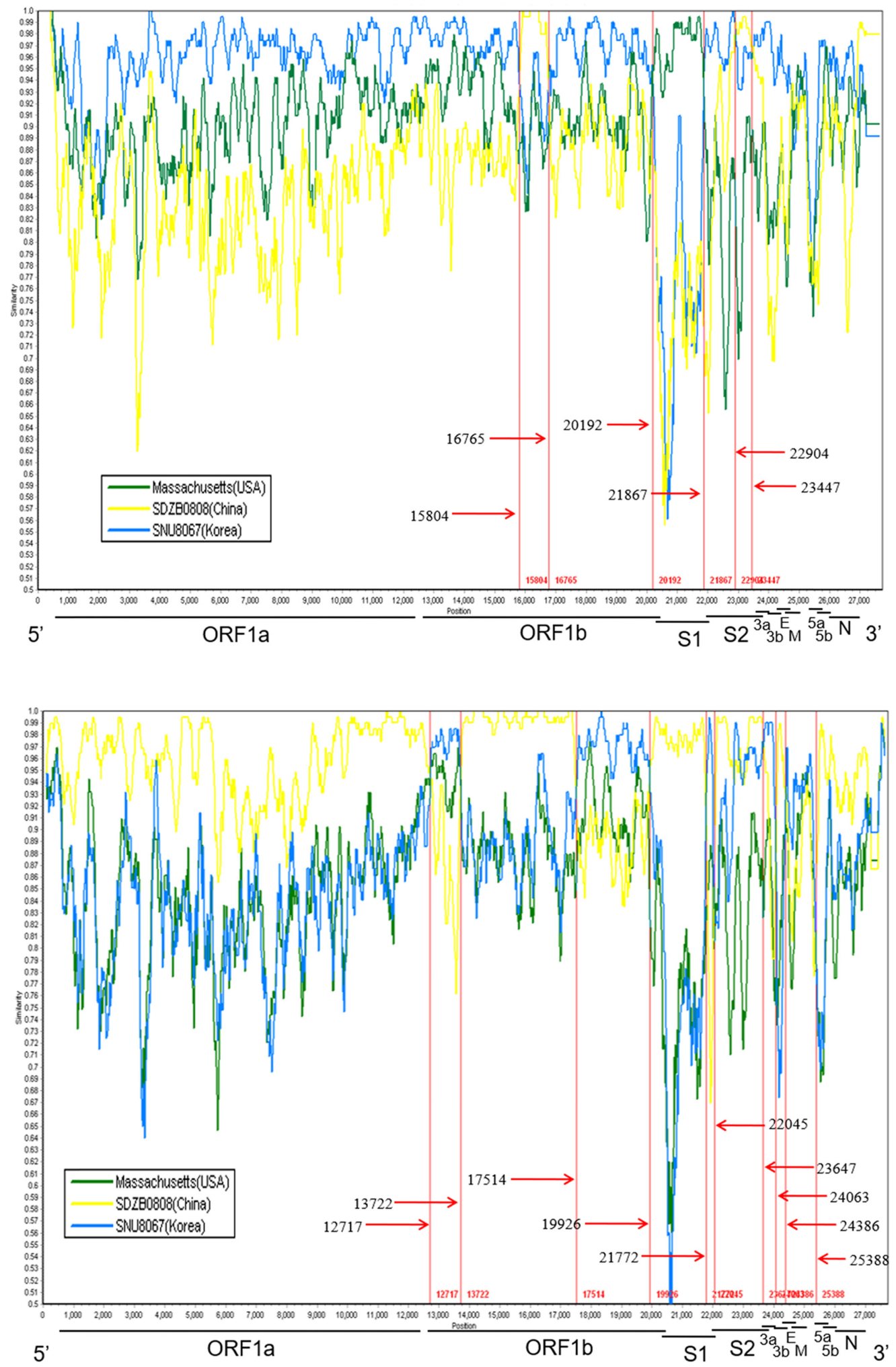

Fig. 2. Simplot analysis of IBV K046-12 (A) and K047-12 (B) isolates. IBV Massachusetts (green), SDZB0808 (yellow), and SNU8067 (blue) strains were used as putative parental strains when IBV K046-12 (A) and K047-12 (B) isolates were queried. The $\mathrm{y}$-axis shows the percentage similarity within a sliding window of $200 \mathrm{bp}$ centered on the position plotted, with a step size between plots of $20 \mathrm{bp}$. The breakpoint where the parental strains have equal identity to the query strain is the predicted recombination site. The genomic positions of the crossover sites were indicated by arrows with numbers. The genomic scale is shown at the bottom of the plot. IBV, infectious bronchitis virus. 
(SDZB0808), and $87.0 \%$ (IBVUkr27-11) to $94.7 \%$ (CK, CH, IBTZ, 2012), respectively (Table 3).

Phylogenetic trees were made based on the nearly complete K046-12 and K047-12 genomes and the genomes of reference IBV strains. The nearly entire genome, $1 \mathrm{a}, 1 \mathrm{~b}, \mathrm{~S} 2$, $\mathrm{E}, \mathrm{M}, 5 \mathrm{a}$, and $\mathrm{N}$ gene of K046-12 were closely related to Korean IBV isolates (SNU8067 and KM91). However, the S1 gene of the K046-12 was uniquely clustered with Masstype IBV strains (H120, Massachusetts). The entire genome, 1a, 1b, S, S1, S2, 3b, E, 5a, 5b, and N gene of K047-12, was closely related to Chinese QX-like IBV strains (SDZB0808, Sczy3, and LX4). Interestingly, the $3 \mathrm{a}$ and $\mathrm{M}$ gene of the K047-12 is clustered with Korean IBV isolates (KM91, SNU8067, and K046-12) (Fig. 1).

\section{Recombination analysis}

Comparative analysis of the genomic SNU8067, SDZB0808, Massachusetts, and K046-12 sequences were performed, and the K046-12 sequence was used as a putative recombinant strain for the detection of the recombination events (Fig. 2). The results of recombination analysis showed that K046-12 was a recombinant strain with the major parental sequence came from KM91-like IBV (SNU8067) and minor parental sequence came from Mass-type IBV (Massachusetts) and QX-like IBV (SDZB0808). The regions of recombination were located at positions 15804-16765, 22904-23447 (higher identity with SDZB 0808), and 20192-21867 (higher identity with Massachusetts). Comparative analysis of the genomic SNU8067, SDZB0808, Massachusetts, and K047-12 sequences was performed, and the K047-12 sequence was used as a putative recombinant strain for the detection of the recombination events (Fig. 2). The results of recombination analysis showed that K047-12 was a recombinant strain with the major parental sequence came from QX-like IBV (SDZB0808) and minor parental sequence came from KM91-like IBV (SNU8067). Regions of recombination were located at positions 12717-13722, 17514-19926, 21772-22045, 23647-24063, and 24386-25388 (higher identity with SNU8067).

\section{Discussion}

IB is currently one of the most influential infectious diseases causing significant damage to poultry production [1]. New IBV variants have continuously emerged from point mutations and recombination. Although preventive vaccines have been used to prevent this disease, complete cross-protective immunity may not occur if the antigenicity of the currently prevalent virus and of the vaccine virus is different. Thus, for efficient control and prevention of IB, sequencing of the genome of the prevalent IBVs is needed to identify antigenicity and evolutionary patterns.

According to sequence comparison and phylogenetic analysis, K046-12 strain was most similar to Korean IBV strains (SNU8067 and KM91) and least similar to QX-type IBVs (Sczy3, SDZB0808, CK, CH, IBTZ, 2012, and LX4). How- ever, the S1 gene of K046-12 had the highest nucleotide sequence identity with $\mathrm{H} 120$ strain at $98.4 \%$. K047-12 strain was most similar to QX-like IBV strains (SDZB0808, Sczy3, CK, CH, IBTZ, 2012 and LX4) and least similar to Masstype IBVs (Massachusetts, H120, and Arkansas vaccine). However, 3a and $\mathrm{M}$ genes were clustered away from other isolates of QX-like IBV (SDZB0808 strain) and were clustered with K046-12 and SNU8067 strains.

Recombination and point mutations are the main mechanisms of the emergence of new variant IBVs [27,29,31]. To verify the phylogenetic tree results, recombination analysis was performed. This study showed that recombination events occurred among traditional Korean IBV strains, QX-like IBV strains and vaccine strains. K046-12 may represent a recombinant strain derived from KM-like field IBV strain (SNU8067) and vaccine strain (H120) which has been extensively used as live vaccine. These results show that recombination of IBV can occur not only between currently prevalent IBVs, but also between current prevalent IBVs and IBVs used as live vaccines [17]. Also, the K047-12 may have been produced naturally by recombination resulting from co-circulation of KM-like field IBV strain (SNU8067) and QX-like field IBV strains. Presently, recombination 'hot spots' are described to be placed adjacent to the putative recombinant crossover sites, and these 'hot spots' are delineated to be AT-rich motifs, e.g., CT(T/G)AACAA, CTT(A/T)(A/T)G [32]. In this study, A-T-rich motifs (CT(T/G)AACAA, CTT(A/T) $(\mathrm{A} / \mathrm{T}) \mathrm{G})$ were discovered in regions adjacent to nearly all the putative crossover sites. However, it is hard to decide whether these motifs were associated with recombination or just appear around the recombinant sites at random [27,33]. Further analysis will be needed to find out whether these motifs are associated with the recombination [28].

The genetic and antigenic characteristics of IBV isolates have been studied principally based on the S1 gene, which is known to induce neutralizing antibodies $[18,22,24,25]$. However, such an analysis focused on the S1 gene alone may produce misleading results for IBV characteristics. In the case of K046-12, the 1ab genes, which are the key genes associated with pathogenicity, are closely related to KM91, but the S1 gene is closely related to Mass-type IBV. Therefore, it is necessary to analyze not only the S1 gene but also other genes including the $1 \mathrm{ab}$ gene in order to use the IBV isolate prevalent in a specific region as a vaccine [34].

In summary, this study shows that new emerging IBV isolates might have arose from recombination among co-circulating traditional Korean IBV strains, QX-like strains, and IBV vaccine strains. For effective IB control, it is necessary to continuously isolate and analyze the currently prevalent IBV, and include other genes, including the $1 \mathrm{ab}$ gene, as well as the S1 gene of IBV isolates. In addition to genetic analyses, the investigation of their antigenicity and pathogenicity, and cross-protection test by using in vivo experiment are needed for suitable vaccine development. 


\section{Acknowledgments}

This study was supported by 2016 Research Grand from Kangwon National University (No. 520160213).

\section{References}

1. Jackwood MW, de Wit S. Infectious bronchitis. In: Diseases of Poultry. 13th ed. pp. 139-159, Iowa state University Press, Ames, 2013.

2. Boursnell ME, Brown TD, Foulds IJ, Green PF, Tomley FM, Binns MM. Completion of the sequence of the genome of the coronavirus avian infectious bronchitis virus. J Gen Virol 1987;68:57-77.

3. Siddell S, Wege H, Ter Meulen V. The biology of coronaviruses. J Gen Virol 1983;64:761-776.

4. Spaan W, Cavanagh D, Horzinek MC. Coronaviruses: structure and genome expression. J Gen Virol 1988;69:2939-2952.

5. Brierley I, Boursnell ME, Binns MM, Bilimoria B, Blok VC, Brown TD, Inglis SC. An efficient ribosomal frame-shifting signal in the polymerase-encoding region of the coronavirus IBV. EMBO J 1987;6:3779-3785.

6. Ziebuhr J, Snijder EJ, Gorbalenya AE. Virus-encoded proteinases and proteolytic processing in the Nidovirales. J Gen Virol 2000;81:853-879.

7. Armesto M, Cavanagh D, Britton P. The replicase gene of avian coronavirus infectious bronchitis virus is a determinant of pathogenicity. PLoS One 2009;4:e7384.

8. Casais R, Dove B, Cavanagh D, Britton P. Recombinant avian infectious bronchitis virus expressing a heterologous spike gene demonstrates that the spike protein is a determinant of cell tropism. J Virol 2003;77:9084-9089.

9. Cavanagh D, Davis PJ, Cook JK, Li D, Kant A, Koch G. Location of the amino acid differences in the S1 spike glycoprotein subunit of closely related serotypes of infectious bronchitis virus. Avian Pathol 1992;21:33-43.

10. Koch G, Hartog L, Kant A, van Roozelaar DJ. Antigenic domains on the peplomer protein of avian infectious bronchitis virus: correlation with biological functions. J Gen Virol 1990; 71:1929-1935.

11. Corse E, Machamer CE. The cytoplasmic tails of infectious bronchitis virus $\mathrm{E}$ and $\mathrm{M}$ proteins mediate their interaction. Virology 2003;312:25-34.

12. Casais R, Davies M, Cavanagh D, Britton P. Gene 5 of the avian coronavirus infectious bronchitis virus is not essential for replication. J Virol 2005;79:8065-8078.

13. Hodgson T, Britton P, Cavanagh D. Neither the RNA nor the proteins of open reading frames $3 \mathrm{a}$ and $3 \mathrm{~b}$ of the coronavirus infectious bronchitis virus are essential for replication. J Virol 2006;80:296-305.

14. Rhee YO, Kim JH, Kim JH, Mo IP, Youn HJ, Choi SH, Namgoong S. Outbreaks of infectious bronchitis in Korea. Korean J Vet Res 1986;26:277-282.

15. Hong SM, Kwon HJ, Kim IH, Mo ML, Kim JH. Comparative genomics of Korean infectious bronchitis viruses (IBVs) and an animal model to evaluate pathogenicity of IBVs to the reproductive organs. Viruses 2012;4:2670-2683.

16. Hong SM, Kwon HJ, Choi KS, Kim JH. Comparative genomics of QX-like infectious bronchitis viruses in Korea. Arch Virol 2017;162:1237-1250.
17. Lim TH, Kim MS, Jang JH, Lee DH, Park JK, Youn HN, Lee JB, Park SY, Choi IS, Song CS. Live attenuated nephropathogenic infectious bronchitis virus vaccine provides broad cross protection against new variant strains. Poult Sci 2012;91:89-94.

18. Mo ML, Hong SM, Kwon HJ, Kim IH, Song CS, Kim JH. Genetic diversity of spike, $3 \mathrm{a}, 3 \mathrm{~b}$ and e genes of infectious bronchitis viruses and emergence of new recombinants in Korea. Viruses 2013;5:550-567.

19. Song JE, Jeong WG, Sung HW, Kwon HM. Sequencing, phylogenetic analysis, and potential recombination events of infectious bronchitis viruses isolated in Korea. Virus Genes 2013;46:371-374.

20. Jackwood MW, Boynton TO, Hilt DA, McKinley ET, Kissinger JC, Paterson AH, Robertson J, Lemke C, McCall AW, Williams SM, Jackwood JW, Byrd LA. Emergence of a group 3 coronavirus through recombination. Virology 2010; 398:98-108.

21. Jang JH, Sung HW, Song CS, Kwon HM. Sequence analysis of the S1 glycoprotein gene of infectious bronchitis viruses: identification of a novel phylogenetic group in Korea. $\mathrm{J}$ Vet Sci 2007;8:401-407.

22. Lee EK, Jeon WJ, Lee YJ, Jeong OM, Choi JG, Kwon JH, Choi KS. Genetic diversity of avian infectious bronchitis virus isolates in Korea between 2003 and 2006. Avian Dis 2008;52:332-337.

23. Lee SK, Sung HW, Kwon HM. S1 glycoprotein gene analysis of infectious bronchitis viruses isolated in Korea. Arch Virol 2004;149:481-494.

24. Lim TH, Lee HJ, Lee DH, Lee YN, Park JK, Youn HN, Kim MS, Lee JB, Park SY, Choi IS, Song CS. An emerging recombinant cluster of nephropathogenic strains of avian infectious bronchitis virus in Korea. Infect Genet Evol 2011; 11:678-685.

25. Lee CW, Jackwood MW. Evidence of genetic diversity generated by recombination among avian coronavirus IBV. Arch Virol 2000;145:2135-2148.

26. Thor SW, Hilt DA, Kissinger JC, Paterson AH, Jackwood MW. Recombination in avian gamma-coronavirus infectious bronchitis virus. Viruses 2011;3:1777-1799.

27. Zhang Y, Wang HN, Wang T, Fan WQ, Zhang AY, Wei K, Tian GB, Yang X. Complete genome sequence and recombination analysis of infectious bronchitis virus attenuated vaccine strain H120. Virus Genes 2010;41:377-388.

28. Zhao F, Zou N, Wang F, Guo M, Liu P, Wen X, Cao S, Huang Y. Analysis of a QX-like avian infectious bronchitis virus genome identified recombination in the region containing the ORF 5a, ORF $5 \mathrm{~b}$, and nucleocapsid protein gene sequences. Virus Genes 2013;46:454-464.

29. Zhou S, Tang M, Jiang Y, Chen X, Shen X, Li J, Dai Y, Zou J. Complete genome sequence of a novel infectious bronchitis virus strain circulating in China with a distinct $\mathrm{S}$ gene. Virus Genes 2014;49:152-156.

30. Lole KS, Bollinger RC, Paranjape RS, Gadkari D, Kulkarni SS, Novak NG, Ingersoll R, Sheppard HW, Ray SC. Fulllength human immunodeficiency virus type 1 genomes from subtype C-infected seroconverters in India, with evidence of intersubtype recombination. J Virol 1999;73:152-160.

31. Denison MR, Graham RL, Donaldson EF, Eckerle LD, Baric RS. Coronaviruses: an RNA proofreading machine regulates 
replication fidelity and diversity. RNA Biol 2011;8:270-279.

32. Wang L, Junker D, Collisson EW. Evidence of natural recombination within the $\mathrm{S} 1$ gene of infectious bronchitis virus. Virology 1993;192:710-716.

33. Brooks JE, Rainer AC, Parr RL, Woolcock P, Hoerr F, Collisson EW. Comparisons of envelope through $5 \mathrm{~B}$ sequences of infectious bronchitis coronaviruses indicates recombination occurs in the envelope and membrane genes. Virus Res 2004;100:191-198

34. Albanese GA, Lee DH, Cheng IN, Hilt DA, Jackwood MW, Jordan BJ. Biological and molecular characterization of ArkGA: a novel Arkansas serotype vaccine that is highly attenuated, efficacious, and protective against homologous challenge. Vaccine 2018;36:6077-6086. 